\title{
Group Training of Spiritual Positivism on Reduction of the Symptoms of Depression, Anxiety, and Stress in Prisoners
}

\author{
Bahman Kord Tamini, ${ }^{1,}$ Iman Lashani, ${ }^{2}$ and Sakine Akbarifar ${ }^{2}$ \\ ${ }^{1}$ Department of Psychology, University of Sistan and Baluchestan, Zahedan, IR Iran \\ ${ }^{2}$ Doroud City Prison, Doroud, IR Iran \\ "Corresponding author: Bahman Kord Tamini, Department of Psychology, University of Sistan and Baluchestan, Zahedan, IR Iran. Tel: +98-9153407469, E-mail: \\ bahman_kord@ped.usb.ac.ir \\ Received 2016 February 18; Revised 2016 May 02; Accepted 2016 June 02.
}

\begin{abstract}
Background: Previous research evidences have shown that group training of spiritual positivism reduces mental symptoms. Objectives: The aim of the present study was to determine the effectiveness of spiritual positivism training on reduction of the symptoms of depression, anxiety, and stress in prisoners.

Methods: The statistical sample consisted of 30 inhabitant prisoners in Doroud city prison that were selected randomly for this study and divided to two groups (15 prisoners in the experimental group and 15 prisoners in the control group). Prisoners in the experimental group were trained for spiritual positivism during 10 sessions. Before and after the intervention and at the fallow up stage, they filled the questionnaire of DASS - 21.

Results: Results of repeated measure; mixed between within subjects analysis of variance indicated that training for spiritual positivism had a significant effect on the reduction of depression, anxiety and stress symptoms in prisoners.

Conclusions: According to the obtained results, it can be suggested that the training of spiritual positivism can be applied as a useful method to reduce the symptoms of depression, anxiety, and stress in prisoners.
\end{abstract}

Keywords: Spiritual Positivism, Depression, Anxiety, Stress, Prisoners

\section{Background}

According to the report of the international health organization, depression disorder is one of the main causes of people's disability. This organization also predicted that by 2020 , this disorder would become the second main disease in respect of human and economic damages (1). Depression and anxiety have a lot of convergences and coverings; and they follow a similar future in affected people. On the other hand, both disorders develop after some prolonged chronic stresses. Three-faced model of stress, anxiety, and depression has been confirmed in many studies (2-4). Stress or mental pressure is an undesirable psychological and physiological mood generated in the reaction to unwilling motives (5). A number of conducted studies on pathology and the criminal's life history have shown that the crime and delinquency increases in psychological disorders (6). Surveying the mental disorders in the Iranian penitentiaries has unwilling motives (5). A number of studies on the pathology and the criminal's history have shown that crime and offense increase in psychological disorders (6). Related results to mental disorders in the Iranian prisoners have shown that $75 \%$ of the under-survey population is affected by mental disorders, $2.32 \%$ by personality disorders (7) 78\% by drug abuse, and $7.48 \%$ by mood disorders (8). The life style of such people involves greater exposure to harmful events, compared to the rest of the society $(9,10)$. One of the ways to deal with accidents and damages is spirituality. It includes a uniting energy connecting all of his individual dimensions through which, the person experiences life. Matthews and Clark (11) have suggested piety as one of the spirituality dimensions. Piety is a personal way to express spirituality through one's own beliefs in oneself and others, and also participation in ceremonies, rituals and practices showing religion. Numerous researches in different countries have shown that people who have spiritual beliefs and perform religious practices have higher mental health and are more adaptable as compared to those who have no such beliefs (12) and receive lower scores in indices including depression, anxiety, psychological distress and damage (13). Such beliefs help people reduce their emotional stress symptoms after an incident (14). Personal beliefs and spirituality assist a person to cope and manage problems and give meaning to life. In addition, spirituality has been an accepted subject in cultures of contemporary societies and has widely been involved in the protection domain $(15,16)$. Having belief in a super power and positive beliefs about oneself and others can influence the reduction of the amount of stress and improve their phys- 
ical and mental health (17). Through providing social support networks, hope, esteem, and emotional and mental relaxation, spirituality also helps better adaptability when encountered by stress (18), and higher spirituality is accompanied with reduced depression symptoms $(19,20)$. Khamis (21) showed that having beliefs regarding spirituality and a super power was related to a low stress score after the incident in Gaza. Spiritual beliefs are accompanied with relaxation about mental stresses and having a method for happier meaningful life. Abdel-Khalek (22) revealed that religious beliefs and spirituality had a positive relationship with quality of life. Moreover, spirituality was negatively related to all general health sub-scales. According to the conducted studies on Islamic religious beliefs, Khodapanahi et al. (23) found that a significant positive relationship was present between religious orientation and adaptability; and also Pourghane et al. (24) demonstrated that there was a negative relationship between stress level and religious beliefs. To analyze the role of religious and spiritual values in stress, it was revealed that people, who have stress symptoms, are on the low or middle level in respect to spiritual beliefs, and the anxiety score of people with low-level spirituality is higher than those with highlevel of spirituality (25). The obtained results from different studies emphasize spirituality effectiveness in health. Moreover, penitentiaries are vulnerable individuals in every society; greater involvement in dangerous behaviors is a characteristic of these individuals, and one contributing factor to such behavior is drug abuse that causes mental diseases and discomfort (26); A considerable population of penitentiaries have symptoms of depression and anxiety, and stress and mental pressure plays a significant role in their routine life. Recognition and practice of methods that protect them from chronic harms such as depression, stress, and other mental disorders is essential, while therapeutic methods seem to be urgent if they have already developed such disorders.

\section{Objectives}

This research attempted to compare the effect of group training of spiritual positivism on the perceived depression, anxiety, and stress of penitentiaries across three time periods (pre - test, post - test, and two months follow-up).

\section{Methods}

The present study had an experimental design with repeated measures that was carried out to compare the effectiveness of group training of spiritual positivism to reduce the level of depression, anxiety and stress in the prisoners' of Doroud prison. For this purpose, 30 prisoners from helpseekers of Doroud penitentiary were selected and placed in two groups (15 in the experimental and 15 in the control group) using a random-numbers table that generated the random sequence.

\subsection{Procedure}

The abstract of the educational session of spiritual positivism was as follows: In this study, it was attempted to apply some capacities including appreciation, thankfulness and generosity to reduce the level of depression, anxiety and stress in prisoners.

1. Writing about spiritual positive characteristics such as thankfulness and generosity, which show the individual's positive traits.

2. Pondering about positive characteristics and how this form of thinking affects people's positively.

3. Recording three positive behaviors of a long day.

4. Preparation of negative feelings such as resentment and annoyance.

5. Writing a forgiveness letter about assaults and bad things done to him and forgiving the involved people.

6. Appreciating those who did some favors for him in the past, that he had not thanked.

7. Discussing the role and importance of positive excitements and their effects in appreciation and the role of positive excitements in individual's outstanding traits.

8. Discussing satisfaction compared to being the best.

9. Discussing optimism and hopefulness: perceiving that an optimistic style about bad incidents is temporary, changeable and situational.

10. Identifying positive characteristics, which are appreciated by others.

\subsection{Study Questionnaire}

\subsubsection{Depression, Anxiety and Stress Scale (DASS - 21)}

This scale was developed by Lovibond and Lovibond (27) to measure the level of depression, anxiety, and stress of prisoners and it contains 21 items, with each item rated from never (0) to always (3); the reliability of this scale using Cronbach's Alpha coefficient in a sample of 717 participants for each sub-scale was as fallows: depression 0.81 , anxiety 0.72 , and stress 0.81 , respectively; and in another study the reliability of this scale for depression was 0.70 , anxiety 0.66 , and stress 0.76 . The Beck depression questionnaire correlated significantly with depression ( $\mathrm{r}$ $=0.66, \mathrm{P}<0.01)$, anxiety $(\mathrm{r}=0.67, \mathrm{P}<0.01)$ and stress $(\mathrm{r}$ $=0.49, \mathrm{P}<0.01)$. 


\section{Results}

To analyze the data, a mixed between-within subjects analysis of variance was conducted to assess the impact of group training of spiritual positivism on participants' scores on perceived depression, anxiety, and stress across three time periods (pre - intervention, post - intervention, and two-month follow up), and results are given in the below tables.

The results of Table 1 show the mean and standard deviation of experimental and control groups regarding depression, anxiety and stress at three time points; preintervention, post-intervention, and follow-up.

Results of multivariate tests revealed that there was a significant interaction between group training of spiritual positivism and time on depression scores [Wilks' Lambda $=0.613, \mathrm{~F}(2,27)=8.50, \mathrm{P}=0.001$, partial eta squared $=$ 0.387 ], anxiety scores [Wilks' Lambda $=0.740, \mathrm{~F}(2,27)=$ $4.73, \mathrm{P}=0.017$, partial eta squared $=0.260]$, and stress scores [Wilks' Lambda $=0.527, \mathrm{~F}(2,27)=12.13, \mathrm{P}=0.0005$, partial eta squared $=0.473]$. There was a substantial main effect of time on the mean scores of depression [Wilks' Lambda $=0.634, \mathrm{~F}(2,27)=7.79, \mathrm{P}=0.002$, partial eta squared $=$ 0.366 ] and stress scores [Wilks' Lambda $=0.569, \mathrm{~F}(2,27)$ $=7.79, \mathrm{P}=0.0005$, partial eta squared $=0.431]$. However, there was no substantial main effect for time on the mean scores of anxiety scores [Wilks' Lambda $=0.939, \mathrm{~F}(2,27)=$ $0.92, \mathrm{P}=0.407$, partial eta squared $=0.064]$. The experimental group showed a reduction in depression, anxiety and stress scores across two time points (pre - intervention and post - intervention) in comparison to the control group, but these changes were not constant for follow up scores of depression, anxiety and stress (see Table 1).

Results of between-subjects effects test revealed that the main effect, comparing the two control and experimental groups, was significant regarding the mean scores of depression for those who received the intervention $[\mathrm{F}(1$, $28)=11.623, P=0.002$, partial eta squared $=0.293$ ], anxiety scores $[\mathrm{F}(1,28)=26.562, \mathrm{P}=0.0005$, partial eta squared $=$ $0.487]$ and stress scores $[\mathrm{F}(1,28)=14.264, \mathrm{P}=0.001$, partial eta squared $=0.338$ ], suggesting a difference in the effectiveness of group training of spiritual positivism.

\section{Discussion}

The present study aimed to assess the effect of spiritual positivism training on the reduction of the depression, anxiety, and stress symptoms of prisoners. Regarding the obtained results, it can be concluded that the training program of spiritual positivism has the capacity to reduce the perceived symptoms of depression, anxiety and stress, and improves the individual's health. Preventively looking, the spiritual positivism education is able to make the individual resistant before being affected by the different mental harms. As shown in this study and other conducted studies in this field, spirituality will grow in a person via a positive mind and behavioral characteristics plus an optimistic style of looking at the world, and paying attention and focusing on what we possess, and appreciating life's positive events. It reduces the individual's cynical beliefs and swifts him towards a satisfying, optimistic, and hopeful life, as found by Miller et al. (19) and Maselko et al. (20). Moreover, spirituality and its beliefs, through creating and emphasizing on a super power, makes a person feel secure and comfortable, and makes them ready to challenge the positive and negative events of life (e.g. anxiety); this claim has been confirmed by several studies such as Al - Mutawa (18), Khamis (21), Goudarzi et al. (14), and Mackenize et al. (17). A spiritual life style, via its own special characteristics, social and behavioral training, invites people to do beneficial, purposeful, and positive activities for themselves, others, and the society; and protects them from dangerous harmful behaviors. In addition, emphasizing on the individual positive and constructing characteristics, spirituality creates positive beliefs about oneself and others, and hence increases self-esteem and allows the construction of effective communications, as found by Koenig, McCullough and Larson (12), Daaleman et al. (15), Parsian and Dunninging (16), and Abdel-Khalek(22). Finally, via increasing life quality, spirituality improves mental and physical health in people and helps them reach their highest capacities and provides a background for their flourishing and loftiness.

\section{Acknowledgments}

We thank the staff of Doroud city Prison and the participants, who friendly helped us with the data collection.

\section{Footnote}

Authors' Contribution: Study concept and design: Sakine Akbarifar; acquisition of data: Iman Lashani; analysis and interpretation of data: Sakine Akbarifar and Iman Lashani; drafting of the manuscript: Bahman Kord Tamini; critical revision of the manuscript for important intellectual content: Bahman Kord Tamini; statistical analysis: Iman Lashani; administrative, technical and material support: Bahman Kord Tamini; study supervision: Bahman Kord Tamini. 
Table 1. Mean and Standard Deviation of Depression, Anxiety and Stress of Experimental and Control Groups During Pre-intervention, Post-intervention, and Follow-up

\begin{tabular}{|c|c|c|c|c|}
\hline Time period & Group & $\mathbf{N}$ & Mean & S.D \\
\hline \multirow{2}{*}{ Pre intervention Depression } & Experiment & 15 & 11.26 & 1.70 \\
\hline & Control & 15 & 11.80 & 2.85 \\
\hline \multirow{2}{*}{ Post intervention Depression } & Experiment & 15 & 7.33 & 2.28 \\
\hline & Control & 15 & 10.73 & 3.97 \\
\hline \multirow{2}{*}{ Fallow up Depression } & Experiment & 15 & 8.80 & 2.07 \\
\hline & Control & 15 & 12.46 & 2.97 \\
\hline \multirow{2}{*}{ Pre intervention Anxiety } & Experiment & 15 & 10.60 & 3.11 \\
\hline & Control & 15 & 11.80 & 2.21 \\
\hline \multirow{2}{*}{ Post intervention test Anxiety } & Experiment & 15 & 7.93 & 2.78 \\
\hline & Control & 15 & 12.66 & 2.99 \\
\hline \multirow{2}{*}{ Fallow up Anxiety } & Experiment & 15 & 8.40 & 2.41 \\
\hline & Control & 15 & 12.73 & 2.52 \\
\hline \multirow{2}{*}{ Pre intervention Stress } & Experiment & 15 & 12.26 & 2.78 \\
\hline & Control & 15 & 12.53 & 3.02 \\
\hline \multirow{2}{*}{ Post intervention Stress } & Experiment & 15 & 7.66 & 2.05 \\
\hline & Control & 15 & 11.93 & 2.57 \\
\hline \multirow{2}{*}{ Fallow up Stress } & Experiment & 15 & 9.73 & 2.76 \\
\hline & Control & 15 & 13.06 & 2.60 \\
\hline
\end{tabular}

\begin{tabular}{|c|c|c|c|c|c|c|c|}
\hline Variable & Effect & Wilks' Lambda & $\mathbf{F}$ & Df1 & Df2 & Sig. & Partial Eta Squared \\
\hline \multirow[t]{2}{*}{ Depression } & Time & 0.634 & 7.79 & 2 & 27 & 0.002 & 0.366 \\
\hline & Time*Group & 0.613 & 8.50 & 2 & 27 & 0.001 & 0.387 \\
\hline \multirow[t]{2}{*}{ Anxiety } & Time & 0.936 & .92 & 2 & 27 & 0.407 & 0.064 \\
\hline & Time*Group & 0.740 & 4.73 & 2 & 27 & 0.017 & 0.260 \\
\hline \multirow[t]{2}{*}{ Stress } & Time & 0.569 & 10.23 & 2 & 27 & 0.0005 & 0.431 \\
\hline & Time ${ }^{*}$ Group & 0.527 & 12.13 & 2 & 27 & 0.0005 & 0.473 \\
\hline
\end{tabular}


Table 3. Results of Between-Subjects Effects Tests of Depression, Anxiety and Stress Between Experimental and Control Groups Across Pre-intervention, Post-intervention and Follow up Assessments

\begin{tabular}{|c|c|c|c|c|c|c|c|}
\hline Variable & Source & Type III Sum of Squares & Df & Mean Square & $\mathbf{F}$ & Sig. & Partial Eta Squared \\
\hline & Intercept & 9734.400 & 1 & 9734.400 & 783.528 & 0.0005 & 0.965 \\
\hline \multirow[t]{3}{*}{ Depression } & Group & 144.400 & 1 & 144.400 & 11.623 & 0.002 & 0.293 \\
\hline & Error & 347.867 & 28 & 12.424 & & & \\
\hline & Intercept & 10282.711 & 1 & 10282.711 & 1036.49 & 0.0005 & 0.974 \\
\hline \multirow{2}{*}{ Anxiety } & Error & 277.778 & 28 & 9.921 & & & \\
\hline & Intercept & 11289.600 & 1 & 11289.600 & 1040.89 & 0.0005 & 0.974 \\
\hline \multirow[t]{2}{*}{ Stress } & Group & 154.711 & 1 & 154.711 & 14.264 & 0.001 & 0.338 \\
\hline & Error & 303.689 & 28 & 10.846 & & & \\
\hline
\end{tabular}

\section{References}

1. Lakdawalla Z, Hankin BL, Mermelstein R. Cognitive theories of depression in children and adolescents: a conceptual and quantitative review. Clin Child Fam Psychol Rev. 2007;10(1):1-24. doi: 10.1007/s10567006-0013-1. [PubMed: 17318382].

2. Imam SS. Depression anxiety stress scales (DASS): Revisited. Int J Behav Sci. 2010;3(1).

3. Polanco-Roman L, Miranda R. Culturally related stress, hopelessness, and vulnerability to depressive symptoms and suicidal ideation in emerging adulthood. Behav Ther. 2013;44(1):75-87. doi: 10.1016/j.beth.2012.07.002. [PubMed: 23312428].

4. Zorumski CF, Paul SM, Izumi Y, Covey DF, Mennerick S. Neurosteroids, stress and depression: potential therapeutic opportunities. Neurosci Biobehav Rev. 2013;37(1):109-22. doi: 10.1016/j.neubiorev.2012.10.005. [PubMed: 23085210].

5. Friedman HS. Health Psychology. New Jersey Prentice;; 2002.

6. Teplin LA, Abram KM, McClelland GM. Prevalence of psychiatric disorders among incarcerated women. I. Pretrial jail detainees. Arch Gen Psychiatry. 1996;53(6):505-12. [PubMed: 8639033].

7. Ashkani H, Dehbozorgi G, Shojae SA. Epidemiology of mental disorders in men residents of Adel abad prison in Shiraz. Periodical Journal of Thought and Behavior. 2002;8(2):4-9.

8. Shariat V, Asadi M, Norouzian M, Pakravan-Nejad M, Yahyazadeh O, Aghayan SH. The prevalence of mental disorders in male prisoners of Qasr prison in Tehran. Tehran Univ Med J TUMS Publications. 2006;64(3):25-36.

9. Dutton DG, Hart SD. Evidence for long-term, specific effects of childhood abuse and neglect on criminal behavior in men. Int J Offender Ther Comp Criminol. 1992;36(2):129-37.

10. Gibson LE, Holt JC, Fondacaro KM, Tang TS, Powell TA, Turbitt EL. An examination of antecedent traumas and psychiatric comorbidity among male inmates with PTSD. J Trauma Stress. 1999;12(3):473-84. doi: 10.1023/A:1024767020280. [PubMed: 10467556].

11. Matthews DA, Clark C. The faith factor: Proof of the healing power of prayer. Penguin; 1999.

12. Koenig HG, McCullough ME, Larson DB. Handbook of Religion and Health.. New York: Oxford University Press; 2001.

13. Koenig HG, George LK, Peterson BL. Religiosity and remission of depression in medically ill older patients. Am J Psychiatry. 1998;155(4):536-42. doi: 10.1176/ajp.155.4.536. [PubMed: 9546001].

14. Goudarzi MA, Shafiei F, Tarikhi A. Relationship between religious attitude and stress disorder symptoms in Bam earthquake-stricken people. Mental Health Principle. 2011;13(2):182-93.
15. Daaleman TP, Kuckelman Cobb A, Frey BB. Spirituality and wellbeing: an exploratory study of the patient perspective. Soc Sci Med. 2001;53(11):1503-11. [PubMed: 11710425].

16. Parsian N, Dunning T. Spirituality and coping in young adults with diabetes. Diabetes Res clinic Prac. 2008;79:SI-SI27.

17. Mackenzie ER, Rajagopal DE, Meibohm M, Lavizzo-Mourey R. Spiritual support and psychological well-being: older adults' perceptions of the religion and health connection. Altern Ther Health Med. 2000;6(6):37-45. [PubMed: 11076445].

18. Al - Mutawa NA. The influence of religion upon the development of post traumatic stress disorder among Kuwaiti prisoners of war. 3 . Long Island University, Conolly College; 2004.

19. Miller L, Warner V, Wickramaratne P, Weissman M. Religiosity and depression: ten-year follow-up of depressed mothers and offspring. J Am Acad Child Adolesc Psychiatry. 1997;36(10):1416-25. doi: 10.1097/00004583-199710000-00024. [PubMed: 9334555].

20. Maselko J, Gilman SE, Buka S. Religious service attendance and spiritual well-being are differentially associated with risk of major depression. Psychol Med. 2009;39(6):1009-17. doi: 10.1017/S0033291708004418. [PubMed: 18834554].

21. Khamis V. Impact of war, religiosity and ideology on PTSD and psychiatric disorders in adolescents from Gaza Strip and South Lebanon. Soc Sci Med. 2012;74(12):2005-11. doi: 10.1016/j.socscimed.2012.02.025. [PubMed: 22483708].

22. Abdel-Khalek AM. Quality of life, subjective well-being, and religiosity in Muslim college students. Qual Life Res. 2010;19(8):1133-43. doi: 10.1007/s11136-010-9676-7. [PubMed: 20585988].

23. Khodapanahi MK, Khaksar Boldaji MA. Relationship between religious orientation and psychological compatibility in university students. Journal of Psychological. 2005;9(3):310-20.

24. Pourghane P, Sharif AE, Zaer SF, Khorsandi M. Survey the effect of religious beliefs in stress reduction in students of langroud faculty of medical sciences. 2010

25. Reazei KH, Qadami MR, Tahmasian M, Qasemi Mobara A, Shirai E. Relationship between the Levels of Religious Values and Stress Rate in the Students of Kermanshah Medical University. Improvement: Scientific Periodical of Kermanshah Medical University. 2010 ;14(1):66-72.

26. Saladin ME, Brady KT, Dansky BS, Kilpatrick DG. Understanding comorbidity between PTSD and substance use disorders: two preliminary investigations. Addict Behav. 1995;20(5):643-55. [PubMed: 8712061].

27. Lovibond PF, Lovibond SH. The structure of negative emotional states: Comparison of the depression anxiety stress scales (dass) with the beck depression and anxiety inventories. Behav Res Ther. 1995;33(3):335-43. 